\title{
Proton Magnetic Resonance Spectroscopy During Initial Treatment With Antipsychotic Medication in Schizophrenia
}

\author{
Juan R Bustillo*, 1,4, Laura M Rowland ${ }^{1,2}$, Rex Jung, ${ }^{2,3,7}$, William M Brooks ${ }^{8}$, Clifford Qualls ${ }^{5}$, \\ Roger Hammond', Blaine Hart ${ }^{6}$ and John Lauriello' \\ 'Department of Psychiatry, University of New Mexico, Albuquerque, NM, USA; '2Department of Psychology, University of New Mexico, \\ Albuquerque, NM, USA; ${ }^{3}$ Department of Neurology, University of New Mexico, Albuquerque, NM, USA; ${ }^{4}$ Department of Neurosciences, \\ University of New Mexico, Albuquerque, NM, USA; ${ }^{5}$ Department of Mathematics, University of New Mexico, Albuquerque, NM, USA; \\ ${ }^{6}$ Department of Radiology, University of New Mexico, Albuquerque, NM, USA; ${ }^{7}$ The Mental Illness and Neuroscience Discovery Institute, \\ University of New Mexico, Albuquerque, NM, USA; ${ }^{8}$ Hoglund Brain Imaging Center, University of Kansas Medical Center, Kansas City, KS, USA
}

Reduced brain N-acetyl-aspartate (NAA) has been repeatedly found in chronic schizophrenia and suggests neuronal loss or dysfunction. However, the potential confounding effect of antipsychotic drugs on NAA has not been resolved. We studied 32 minimally treated schizophrenia patients and 21 healthy subjects with single-voxel proton magnetic resonance spectroscopy ( $\left.{ }^{H} \mathrm{H}-\mathrm{MRS}\right)$ of the frontal and occipital lobes, caudate nucleus, and cerebellum. Concentrations of NAA, Choline, and Cre were determined and corrected for the proportion of cerebrospinal fluid (CSF) in the voxel. Patients were treated in a randomized-controlled double-blind manner with either haloperidol or quetiapine. 'H-MRS was repeated every 6 months for up to 2 years. There was a group main effect for baseline NAA with lower global NAA in schizophrenia subjects before treatment compared to healthy controls. Global NAA was directly related to measures of global cognitive performance in the whole subject sample. Following treatment with haloperidol or quetiapine, there were no changes in NAA in any of the regions studied. Early in the illness, schizophrenia patients already demonstrate subtle reductions in NAA. Treatment with typical or atypical antipsychotic medications for several months does not result in NAA changes. Neuropsychopharmacology (2008) 33, 2456-2466; doi:I0.1038/sj.npp. I 30163 I; published online 19 December 2007

Keywords: 'H-MRS; schizophrenia; N-acetyl-aspartate; antipsychotic drug; haloperidol; quetiapine

\section{INTRODUCTION}

Proton magnetic resonance spectroscopy $\left({ }^{1} \mathrm{H}-\mathrm{MRS}\right)$ measures specific brain metabolites including $\mathrm{N}$-acetylaspartate (NAA), choline (Cho), and creatine (Cre) in vivo (Weiner et al, 1989; Brooks et al, 1999a). Produced in the neuronal mitochondria, NAA is considered a marker of neuronal integrity and viability and predicts severity of illness in various neurodegenerative disorders (Brooks et al, 1997, 1999b; Friedman et al, 1998). Consistently, NAA correlates with cognitive function in brain disorders (Ross and Sachdev, 2004). A recent meta-analysis of $64{ }^{1} \mathrm{H}-\mathrm{MRS}$ studies of schizophrenia patients found significant NAA reductions in frontal and medial temporal regions, with no evidence of differences between patient groups studied early or late in the illness (Steen et al, 2005). However, most of

*Correspondence: Dr JR Bustillo, Department of Psychiatry MSC09 5030, I University of New Mexico, Albuquerque, NM 87131-0001, USA, Tel: + I 505272 558|, Fax: + I 5052725572 ,

E-mail: jbustillo@salud.unm.edu

Received 27 April 2007; revised 18 October 2007; accepted 19 October 2007 these studies included chronically ill patients treated for many years.

Few longitudinal studies of patients early in the illness have been reported. Of these, Choe et al (1996) found no changes in NAA with treatment, whereas Fannon et al (2003) found evidence that atypical antipsychotic treatment was associated with an increase in NAA. Our preliminary report (10 schizophrenia patients from the current sample) suggested NAA reductions with antipsychotic treatment (Bustillo et al, 2002). The effect of treatment with typical and atypical antipsychotic medications on ${ }^{1} \mathrm{H}-\mathrm{MRS}$ measures has not been systematically studied.

Several factors may account for these inconsistent findings, such as differences in patients or spectroscopic methodology. In terms of patient characteristics, the impact of antipsychotic medication or the length of illness is rarely considered in these studies (hence, the potential impact of medication was a central focus in the present investigation). Also many studies have been underpowered (Steen et al, 2005). Variation in ${ }^{1} \mathrm{H}-\mathrm{MRS}$ technique include (1) spectroscopic acquisition (single-voxel $v s$ chemical shift imaging and varying echo time (TE)), (2) use of ratios (NAA to Cre or Cho) vs metabolite concentrations, (3) spectral 
quantification and correction for proportion of spectroscopic voxel cerebrospinal fluid (CSF), and (4) reproducibility of ${ }^{1} \mathrm{H}$-MRS in the schizophrenia population.

Here, we report results from our completed sample of early schizophrenia patients with minimal previous antipsychotic exposure. Patients were scanned at baseline and then randomized to double blind treatment with haloperidol or quetiapine and followed with repeated ${ }^{1} \mathrm{H}$-MRS for up to 2 years. Healthy volunteers were also followed longitudinally. We used a reliable (Mullins et al, 2003) single-voxel spectral acquisition technique with a short TE $(40 \mathrm{~ms})$ and corrected for voxel CSF. Because of our previous finding of lower frontal NAA with haloperidol but not with clozapine in chronically treated patients (Bustillo et al, 2001), we hypothesized a differential reduction of NAA with haloperidol treatment in schizophrenia patients. We also hypothesized that NAA would be directly correlated with cognitive performance but not with psychiatric symptom measures.

\section{MATERIALS AND METHODS}

\section{Subjects}

Patients were recruited from the Mental Health Center at the University of New Mexico (UNM). Inclusion criteria were (1) DSM-IV diagnosis of schizophrenia, schizoaffective, or schizophreniform disorder made through consensus by two research psychiatrists (JL and JB), using all available information derived from the structured clinical interview for DSM-IV patient version (SCID-P; First et al, 1995a), review of medical and psychiatric records and family informants; (2) lifetime antipsychotic exposure of less than 3 weeks. Exclusion criteria were diagnosis of neurological disorder or unstable systemic medical illness with neurological complications, mental retardation, history of severe head trauma, or substance use disorder not fully remitted (except for nicotine). Healthy subjects were recruited for this study from the community and the UNM campus and were excluded if they had (1) any DSM-IV axis I disorder, determined by structured clinical interview for DSM-IV nonpatient version (SCID-NP; First et al, 1995b); (2) firstdegree relatives with schizophrenia or other psychotic disorders; (3) history of neurological disorder. All subjects gave written informed consent prior to entry into the study and were paid for their participation. The study was approved by the local Institutional Review Board.

\section{Demographic and Clinical Characteristics}

A total of 32 patients and 21 controls were studied (Table 1). All patients met diagnosis of schizophrenia. There were no significant differences between the patient and control groups in age (mean $=24.7$ years, $\mathrm{SD}=6.9 v s$ mean $=24.7$ years, $S D=5.3)$, male/female proportion $(26 / 6$ vs 18/3), or handedness (right/left: 27/4 vs 20/1), respectively. The schizophrenia group had fewer years of education $(12, \mathrm{SD}=1.9$ vs $14, \mathrm{SD}=1 ; \mathrm{t}(51)=-6.41, p=0.003)$. The groups also differed in ethnic composition (AfricanAmerican/Caucasian/Hispanic: 5/7/20 for patients vs 0/16/ 5 for controls; $\left.\chi^{2}=16 ; \mathrm{df}=2,18 ; p<0.001\right)$.
Table I Demographic and Clinical Characteristics of the Sample

\begin{tabular}{|c|c|c|}
\hline & $\begin{array}{l}\text { Schizophrenia } \\
\quad(N=32)\end{array}$ & $\begin{array}{l}\text { Healthy } \\
\text { controls } \\
(N=2 I)\end{array}$ \\
\hline Age $(S D)$ years & $24.7(6.9)$ & $24.7(5.3)$ \\
\hline Gender (male/female) & $26 / 6$ & $18 / 3$ \\
\hline Ethnicity (African-American/White/Hispanic) & $5 / 7 / 20$ & $0 / 16 / 5 *$ \\
\hline Education (SD) years & $12(1.9)$ & $14(1.0)^{*}$ \\
\hline Handedness (right/left) & $27 / 4$ & $20 / 1$ \\
\hline Length of illness (SD) months & $41.4(69)$ & NA \\
\hline $\begin{array}{l}\text { Never-treated/minimally treated }(<3 \\
\text { weeks) }\end{array}$ & $15 / 17$ & NA \\
\hline $\begin{array}{l}\text { Number of patients minimally treated with: } \\
\text { (and mean dose; } \mathrm{mg} \text { ): }\end{array}$ & & NA \\
\hline Risperidone & $8(3.9)$ & NA \\
\hline Olanzapine & $4(10)$ & NA \\
\hline Haloperidol & $3(1.3)$ & NA \\
\hline Quetiapine & $2(375)$ & NA \\
\hline Randomized to haloperidol/quetiapine & $15 / 17$ & NA \\
\hline Positive symptoms (SD) & $21(5.4)$ & NA \\
\hline Negative symptoms (SD) & $19(8.3)$ & NA \\
\hline General symptoms (SD) & $35(7.6)$ & NA \\
\hline
\end{tabular}

Abbreviation: SD, standard deviation.

$* p<0.05$.

The schizophrenia group had a mean length of untreated psychotic symptoms of 41 months $(S D=69)$. A total of 15 patients were antipsychotic-naive at the time of the baseline scan and 17 had received minimal treatment $(<3$ weeks lifetime exposure as per inclusion criteria). Of these, eight patients took risperidone (mean $3.9 \mathrm{mg} /$ day), four took olanzapine $(10 \mathrm{mg} /$ day $)$, three took haloperidol $(1.3 \mathrm{mg} /$ day $)$ and two took quetiapine $(375 \mathrm{mg} /$ day $)$ in the days prior to the baseline scan. The schizophrenia group exhibited moderate levels of psychopathology at baseline: positive symptoms scale $=21, \mathrm{SD}=5.4$; negative symptoms scale $=19, \mathrm{SD}=8.3$; general symptoms scale: $35, \mathrm{SD}=7.6$.

\section{Magnetic Resonance Studies}

Studies were completed in a $1.5 \mathrm{~T}$ magnetic resonance imager (Signa, GE Medical Systems). A T1-weighted $1.5 \mathrm{~mm}$ contiguous axial sequence covering the whole brain was acquired (fast-SPGR, TE $=6.9 \mathrm{~ms}, \mathrm{TR}=17.7 \mathrm{~ms}$, flip $=25^{\circ}$, $256 \times 192$ matrix, $1.5 \mathrm{~mm}$ contiguous slices). Single-voxel spectra were acquired with point-resolved spectroscopy (PRESS; $\mathrm{TE}=40 \mathrm{~ms}, \quad \mathrm{TR}=2000 \mathrm{~ms}$, spectral width $=$ $2000 \mathrm{~Hz}, 1024$ data points used, 128 water-suppressed, and 32 water-unsuppressed averages). An automated routine was used to optimize field homogeneity, radiofrequency pulse power, and water suppression pulse flip angles for each voxel. Spectroscopic voxels were selected in the left caudate (volume $=6 \mathrm{cc}$ ), left frontal and occipital lobes $(12.6 \mathrm{cc})$, and right cerebellum $(12.6 \mathrm{cc})$ using the T1-weighted imaging series (Figure 1). To control for head tilt, a standardized method of left frontal and occipital voxels prescription was implemented to select the inferiorsuperior plane (see Jung et al, 2002). The anterior-posterior 

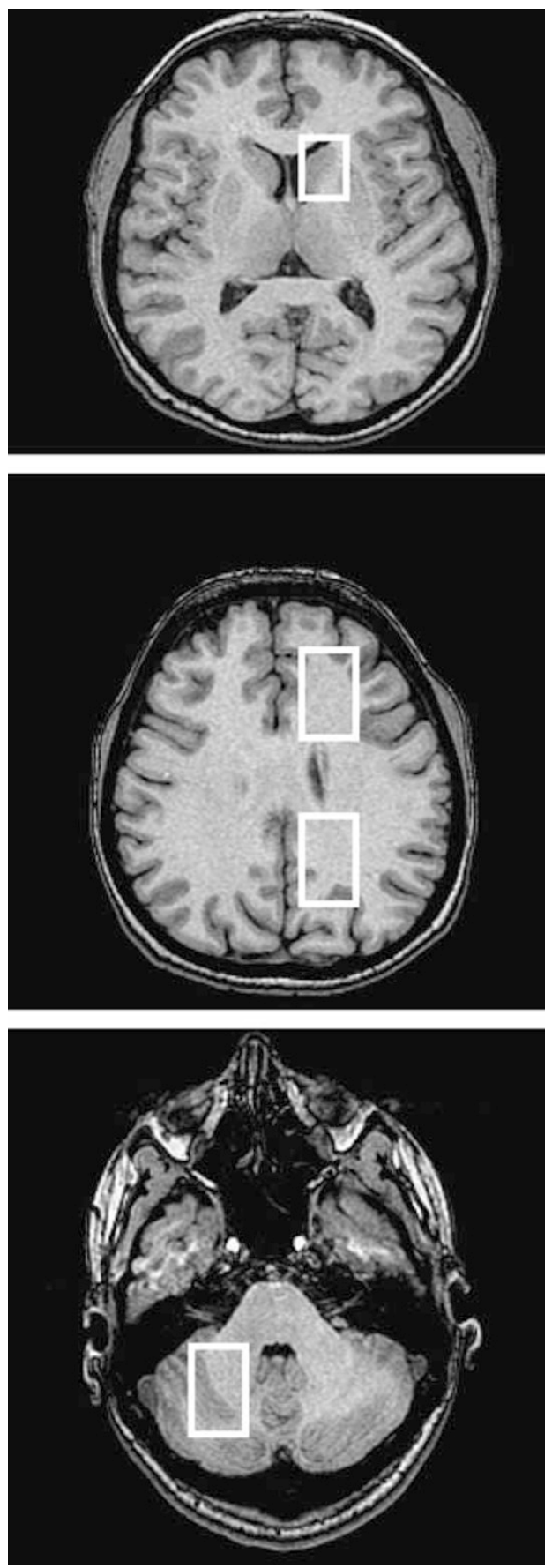

Figure I Voxel placement in four regions of interest: left caudate, frontal and occipital lobes, and right cerebellum.

and lateral placement varied individually to maximize white matter and minimize CSF inclusion as determined by visual inspection. The left caudate voxel was prescribed in the caudate head to encompass the maximum amount of gray matter. The right cerebellar voxel was prescribed in the right cerebellar hemisphere so that it encompassed the maximum amount of gray matter. For the follow-up scan, the same rules were used; in addition the MR operator utilized the initial set of films illustrating the voxel placement in relationship to the individual ventricular, sulcal, and gyral patterns as further guidance as described previously (Brooks et al, 1999a).

Spectroscopic data were transferred to a Sun UltraSparcstation (SunMicrosystems, Mountain View, CA) for analysis. All data were processed by one operator blinded to subject identity, medication status, and scanning time. Water suppressed spectra were analyzed using LCModel version 6.0 (Provencher, 1993), a fully-automated, commercially available curve-fitting software that uses a least squares analysis method for estimating metabolite concentrations. The quantification model included the following metabolites in the basis set: aspartate, creatine, $\gamma$-aminobutyric-acid, glucose, glutamine, glutamate, inositol, $\mathrm{N}$-acetyl-aspartate, $\mathrm{N}$-acetyl-aspartate-glutamate (NAAG), phosphocholine (Cho), scylloinositol, taurine, and guanidine. For each spectrum, the area under each peak was normalized to the unsuppressed water peak (corrected for water T1 relaxation as per Barker et al, 1993), allowing metabolite concentrations of total NAA (ie NAA + NAAG), Cho, and Cre. To ensure high-quality data, any data set that met one or more of the following criteria was rejected: (a) obvious movement artifact on imaging or spectroscopy; (b) metabolite FWHM greater than 0.1 p.p.m.; and (c) metabolite fitting uncertainties (\%SD) greater than 20 in the LCModel output.

The T1-weighted images corresponding to the spectroscopic voxels were analyzed using automated $\mathrm{k}$-means segmentation described previously (Petropoulos et al, 1999) to quantify CSF, white, and gray matter. The percentage of tissue within each spectroscopic voxel (CSF, gray, and white matter) was then calculated by creating a mask corresponding to each voxel location and superimposing this mask on the segmented images. Spectroscopic values were then corrected for CSF fraction within the voxel assuming that CSF has NAA, Cre, and Cho concentrations of zero by a simple arithmetic. For example, if the voxel tissue component (gray plus white matter) was $90 \%$, the LC model yielded concentration was divided by 0.9 for the final concentration. We have previously documented very good test-retest reliability with these methods (Brooks et al, 1999a; Mullins et al, 2003). Specifically, in our test-retest study in 12 stable patients with chronic schizophrenia using the same single voxel PRESS technique, we found coefficients of variation $(\mathrm{CV})$ for the three metabolites between 2 and $3 \%$ in the frontal voxel and 4 and $12 \%$ for the caudate (Mullins et al, 2003). Hence, we expected to be able to detect a $0.3 \mathrm{mM}$ change $(3 \%)$ in frontal NAA with $80 \%$ power and $\alpha=0.05$, with 20 schizophrenia patients scanned at least twice.

\section{Neuropsychological Assessments}

At baseline, schizophrenia patients and healthy subjects completed a broad neuropsychological battery which included Attention Process Training Test (APT 1, 2, and 3), Controlled Oral Word Association Test, Stroop Interference Test, Vocabulary, Digit span (subtests from the WAIS-III; Wechsler, 1997), Finger Tapping Test (dominant and nondominant hands) and Grooved Pegboard Test (dominant and nondominant hands) (Lezak et al (2004)). 


\section{Drug Trial}

Following MR scanning, schizophrenia patients were randomized 1-1 to double-blind haloperidol or quetiapine. Dosage was flexible and determined by the treating physician to optimize clinical response and minimize side effects. The haloperidol dose range allowed was between 2 and $12 \mathrm{mg}$ and for quetiapine between 100 and $600 \mathrm{mg}$ a day. The overall intent was for patients to remain on their randomized drug assignment for a period of 2 years and to be scanned at approximately 6-month intervals. Patients with poor clinical response or persistent significant side effects, as determined by the treating psychiatrist, had their next scheduled ${ }^{1} \mathrm{H}-\mathrm{MRS}$ completed early, prior to being blindly switched to the other antipsychotic (quetiapine or haloperidol).

The patients were assessed with the Positive and Negative Symptoms Scale (PANSS; Kay et al, 1987), the SimpsonAngus Scale (SAS; Simpson and Angus, 1970) for parkinsonism, the Barnes Akathisia Rating Scale (BARS; Barnes, 1989) for akathisia, and the Abnormal Involuntary Movements Scale (AIMS; Guy, 1976) for tardive dyskinesia at monthly intervals.

\section{Statistical Analyses}

Dependent variables of interest were CSF-corrected NAA (main metabolite of interest), Cho, and Cre concentrations in millimoles per liter of tissue $(\mathrm{mM})$. The overall analyses used PROC Mixed (SAS version 8), an analysis of variance (ANOVA), with subject group as the grouping factor and time of scan (baseline and last observation carried forward (LOCF)) and brain region as repeated factors. In a second approach to study progressive changes for the three metabolites, we calculated a slope for each subject in each region. We used all available data (at least 2 and up to 5 values) with their intervals in months, and fitted a regression line as an estimate of change in the metabolite's concentration per month of follow-up. PROC Mixed for slopes and for baseline metabolites had brain region as the repeated factor. To further understand significant overall effects, post hoc tests were done with Fisher's least significance difference method. The relationships between metabolite concentrations and demographic, clinical characteristics, and neuropsychological performance were analyzed with Pearson's correlations. Demographic and clinical characteristics of the sample were compared between groups with $t$-tests for continuous data, and $\chi^{2}$-tests or Fisher's exact tests for nominal data.

\section{RESULTS}

\section{Baseline Analyses}

Neurometabolites. The mean (and SD) measures of spectral quality (FWHM and signal-to-noise-ratio (SNR), from LC model output) for each region of interest were caudate, $\mathrm{FWHM}=0.076(0.02), \mathrm{SNR}=7.5$ (4.0) for schizophrenia and $\mathrm{FWHM}=0.08(0.02), \mathrm{SNR}=6(2.16)$ for controls; frontal, FWHM $=0.055$ (0.01), SNR = 17.6 (4.8) for schizophrenia and $\mathrm{FWHM}=0.05(0.008), \mathrm{SNR}=18.5$ (3.5) for controls; occipital, FWHM $=0.05$ (0.01), $\mathrm{SNR}=20.9$ (5.8) for schizophrenia and $\mathrm{FWHM}=0.04(0.008), \mathrm{SNR}=23.2$
(3.6) for controls; and cerebellar, FWHM=0.06 (0.02), $\mathrm{SNR}=14.3(4.7)$ for schizophrenia and $\mathrm{FWHM}=0.06$ (0.01), SNR = 11.26 (2.18) for control. Metabolite values at baseline are presented in Figure 2. For NAA, the main metabolite of interest, we found that frontal, occipital, caudate, and cerebellar concentrations at baseline did not differ significantly between the patient and control groups (group by region interaction $\mathrm{F}(3,147)=0.34, p=0.8$ ). However, there was a significant group main effect $(\mathrm{F}(1,51)=6.4, p=0.01)$ consistent with a global NAA reduction in patients with schizophrenia for the four regions combined. Also, there was a region main effect $(\mathrm{F}(3,147)=12.1, p<0.001)$ with lower NAA in the caudate compared to the other regions. Since there was a slight difference between groups in gray/white matter proportion in the occipital voxel (schizophrenia $=0.15, \mathrm{SD}=0.04 \mathrm{vs}$ control $=0.12, \mathrm{SD}=0.04 ; \mathrm{t}(1,51)=2.6, p=0.01)$, we added gray matter proportion for all voxels as a covariate in the Proc Mixed ANOVA model. The main effect of group remained $(\mathrm{F}(1,51)=6.5, p=0.01)$ as well as the main effect of region $(F(3,145)=12, p<0.001)$, while there was no effect of gray matter proportion $(\mathrm{F}(1,145)=0.15, p=0.7)$. Finally, re-analyses after excluding left-handed subjects (four schizophrenia and one controls), confirmed no group by region interaction $(p=0.97)$, but persistence of the group main effect $(\mathrm{F}(1,46)=5.9, p=0.02)$, with lower global NAA in the schizophrenia group.

There was no difference in NAA between minimally treated and antipsychotic-naive schizophrenia subgroups $(\mathrm{F}(1,30)=0.53, p=0.5)$ and the baseline average NAA was not related to duration of illness $(r(31)=-0.2, p=0.3)$. Also, baseline average NAA levels were not related to severity of positive $(r(31)=-0.1, p=0.6)$, negative $(r(31)=0.01, p=0.9)$ or general symptoms $(r(31)=-0.1$, $p=0.5)$. Finally, including ethnicity and education level as covariates, did not meaningfully change the group main

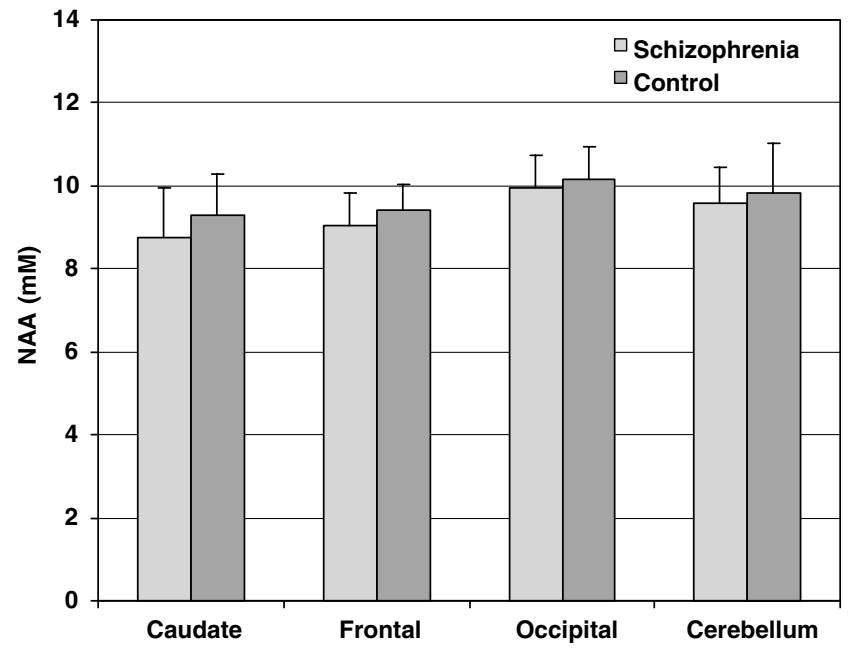

Figure 2 Baseline mean $N$-acetyl-aspartate (NAA) levels in minimally treated schizophrenia patients and healthy volunteers. ANOVA group main effect $F(I, 5 I)=6.4 ; p=0.01$. Post hoc tests for each region were caudate, $\mathrm{t}(1,44)=-1.72, p=0.09 ;$ frontal, $\mathrm{t}(1,49)=-1.77, p=0.08 ;$ occipital, $\mathrm{t}(\mathrm{I}, 43)=-0.92, p=0.36$; and cerebellar, $\mathrm{t}(\mathrm{I}, 29)=-0.71, p=0.48$. Error bars are SD. 
effect on NAA when comparing the schizophrenia and control groups: $\mathrm{F}(1,49)=3.18, p=0.08$ and $\mathrm{F}(1,49)=4.27$, $p=0.04$, respectively.

Repeated measures ANOVA revealed that frontal, occipital, caudate, and cerebellar Cho concentrations at baseline did not differ significantly between the patient and control groups (group by region interaction $\mathrm{F}(3,144)=0.62, p=0.6)$. There was a trend for a group main effect $(F(1,51)=3.4, p=0.07)$ suggestive of a global Cho reduction in schizophrenia for the four regions combined. Also, there was a region main effect $(F(3,144)=9.1, p<0.001)$ with lower Cho in the occipital lobe.

For Cre, repeated measures ANOVA for the four regions at baseline found a significant group by region interaction $\mathrm{F}=(3,147)=4.8, p=0.003)$, with lower Cre in the caudate in the schizophrenia group (confirmed by post hoc $t$-test, $p=0.01)$. There was no group main effect $(\mathrm{F}(1,51)=0.11$,

Table 2 Factor Analysis of Neuropsychological Performance in Minimally Treated Schizophrenia and Healthy Subjects

\begin{tabular}{lccc}
\hline & Factor I & Factor 2 & Factor 3 \\
\hline APT3 & $89^{\mathrm{a}}$ & 11 & 25 \\
APT2 & $85^{\mathrm{a}}$ & 10 & 21 \\
Fluency & $62^{\mathrm{a}}$ & 25 & 16 \\
Stroop & $60^{\mathrm{a}}$ & 24 & $49^{\mathrm{a}}$ \\
Vocabulary & $59^{\mathrm{a}}$ & 26 & 42 \\
Digits backward & $57^{\mathrm{a}}$ & 48 & 7 \\
Tap dominant & 13 & $85^{\mathrm{a}}$ & 22 \\
Tap nondominant & 12 & $84^{\mathrm{a}}$ & 8 \\
Digits forward & 41 & $66^{\mathrm{a}}$ & 14 \\
Pegboard dominant & 29 & 10 & $88^{\mathrm{a}}$ \\
Pegboard nondominant & 19 & 18 & $87^{\mathrm{a}}$ \\
\hline
\end{tabular}

Abbreviation: APT, Attention Process Training Test.

'Values $>48$ are flagged by '**' $p=0.7)$. Also, there was a region main effect $(\mathrm{F}(3,147)=$ 91.2, $p<0.001$ ) with higher Cre in the cerebellum. Covarying GM voxel proportion had no main effect $(\mathrm{F}(1,145)=1.7, \quad p=0.2)$ and the interaction remained $(\mathrm{F}(3,145)=4.7, p=0.004)$. Also, baseline caudate Cre levels were not related to severity of positive $(r(30)=-0.07$, $p=0.7)$, negative $(r(30)=0.03, \quad p=0.9), \quad$ or general symptoms $(r(30)=0.3, p=0.1)$.

Neuropsychological testing. Individual neuropsychological test scores were significantly worse in the schizophrenia patients compared to the healthy control group (all $t$-tests between 2.4 and 5.9 and all p's between 0.02 and $<0.001$ ). Schizophrenia patients randomized to haloperidol $v s$ quetiapine did not differ in performance (all $t$-tests between 1.4 and -0.05 and all $p$ 's between 0.2 and 0.96 ).

Neuropsychological data underwent a factor analysis with VARIMAX rotation to identify groups of tests that varied together and would meaningfully suggest separate cognitive domains. The first principal component extracted from broad batteries of cognitive measures was first identified by Spearman (1904) as ' $g$ ' representing a general factor of intelligence. Three factors were retained that explained $71 \%$ of the variance based on eigenvalues. APT trial 1 was excluded because it did not load with any of the factors.

Factors and their loadings are presented in Table 2 (APT 1 was excluded since it did not significantly load with any of the three factors). Factor 1, suggestive of general cognitive function, ' $g$ ' (Jensen, 1998), correlated significantly with mean NAA across the four regions for the whole subject sample $(r(42)=0.4, p=0.008$; Figure 3$)$. This correlation was clearly carried by the schizophrenia $(r(23)=0.43$, $p=0.05)$ and not the control group $(r(21)=0.24$, $p=0.29)$. Factor 2, suggestive of motor speed, correlated with cerebellar Cho $(r(40)=0.38, p=0.01)$. Finally Factor 3 , suggestive of motor dexterity, correlated with caudate NAA $(r(39)=0.33, p=0.04)$ and caudate Cre $(r(39)=0.39$, $p=0.01)$. No other significant correlations were found

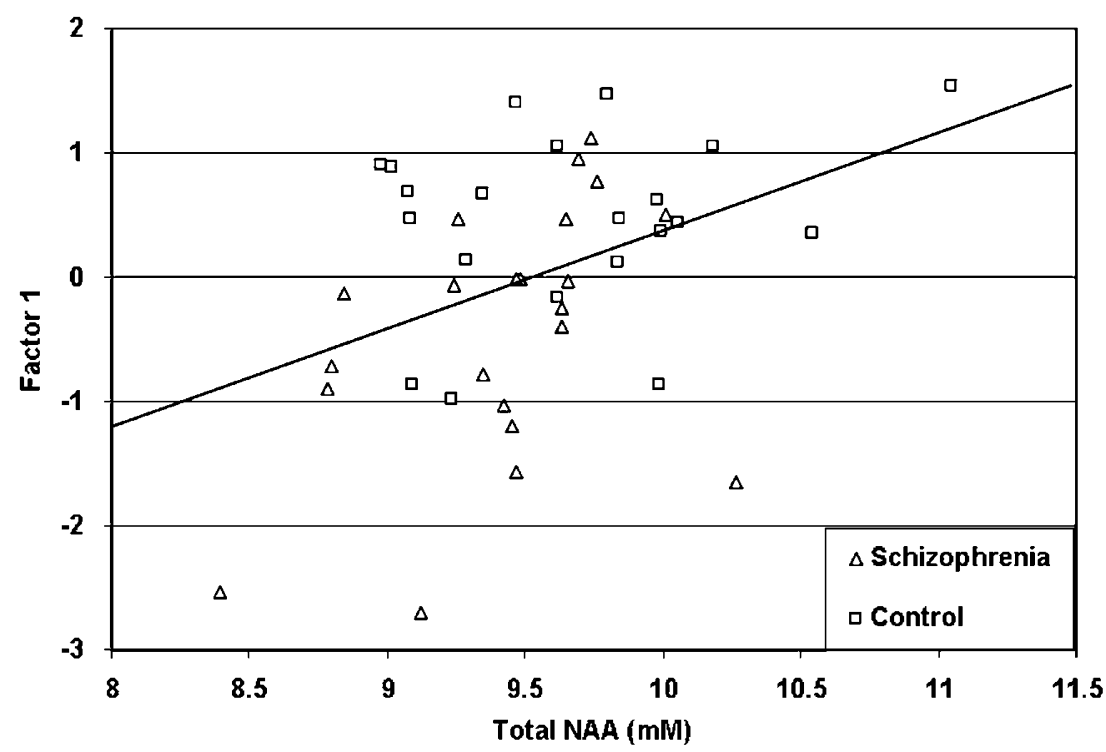

Figure 3 Correlation between general cognition (factor I from factor analysis) and global N-acetyl-aspartate (NAA) (across four regions) in combined sample of minimally treated schizophrenia and healthy control subjects. $r(42)=0.4 ; p=0.008$. 
between the three factors and any of the other three metabolite concentrations in any of the four individual or combined regions.

\section{Longitudinal Analyses}

After baseline assessments, patients and healthy subjects were followed for a similar number of months: $9.4, \mathrm{SD}=8.7$ vs 9.0, $\mathrm{SD}=4.2$, respectively, $(\mathrm{t}(1,47)=0.24, \quad p=0.8)$. Patients were randomized to treatment with haloperidol $(n=15)$ or quetiapine $(n=17)$. Four patients from each treatment group were switched to the other drug because of poor tolerability. Nine patients dropped out and were lost to follow-up without a second MRS scan: seven randomized to quetiapine, two to haloperidol. Two (one randomized to each drug) were no longer receiving either study drug at follow-up due to resolution of psychosis, but had a final scan. One patient had poor tolerance to both study drugs and had his last scan while treated with olanzapine. We found no significant difference in the distribution of study drug at time of last scan between the two randomized groups (Fisher's exact test, $p=0.14$ ). Hence, at the last MRS scan 12 patients were being treated with haloperidol, 8 with quetiapine.

Two types of follow-up analyses were undertaken: baseline vs LOCF and analysis of slopes. Repeated measures ANOVA comparing baseline with LOCF for NAA concentrations across the four regions in the schizophrenia and healthy control groups showed no two- or three-way interactions (all $p$ 's $>0.05$ ). Likewise, there was no main effect of time $(\mathrm{F}(1,39)=0.46, p=0.5)$. However, a group main effect remained $(\mathrm{F}(1,38)=5.4, p=0.03)$, consistent with the baseline findings, and suggestive of persistently reduced global NAA in the schizophrenia group despite antipsychotic treatment (Table 3 ). The region main effect also remained consistent with lower NAA in the caudate $(\mathrm{F}(3,111)=18, p<0.001)$. Similar analyses of schizophrenia subjects based on antipsychotic drug taken at the time of last ${ }^{1} \mathrm{H}$-MRS found no differential effect of medication on NAA concentrations $(\mathrm{F}(1,18)=0.84, p=0.4)$. LOCF analyses for Cho and Cre were also not suggestive of a change overtime comparing schizophrenia and control groups or haloperidol and quetiapine-treated groups (analyses not shown).

Analysis of slopes of NAA showed no significant differences between healthy subjects and schizophrenia groups $(\mathrm{F}(1,36)=2.6, p=0.1)$ or among the patients treated with quetiapine and haloperidol $(\mathrm{F}(1,18)=0.27$, $p=0.7)$. Also, slopes did not significantly differ between the haloperidol and healthy control groups $(\mathrm{F}(1,26)=1.52$, $p=0.23)$ or the quetiapine and control groups $(\mathrm{F}(1,22)=$ $0.92, p=0.35)$. Likewise, slopes for Cho and Cre did not differ by treatment or between the healthy subjects and schizophrenia groups (analyses not shown).

Patients clearly benefited from antipsychotic treatment and at the time of the last follow-up scan positive and general symptoms had improved, with no differential effect of study drug (interactive effects were all nonsignificant). For positive symptoms, there was a significant main effect of time $(\mathrm{F}(1,12)=30, p<0.001)$ and no study-drug main effect $(\mathrm{F}(1,21)=0.9, p=0.34)$, consistent with no differential benefits for either medication. Similarly, for general symptoms there was a significant main effect of time $(\mathrm{F}(1,11)=17.5, p=0.002)$ and no study-drug main effect $(\mathrm{F}(1,21)=0.9, \quad p=0.34)$. However, negative symptoms failed to improve overtime $(\mathrm{F}(1,12)=1.8, p=0.2)$.

Neuro-motoric side effects were minimal with either treatment (interactive effects were all nonsignificant). For AIMS, there was no main effect of time $(\mathrm{F}(1,11)=1.0$, $p=0.33)$ and no study-drug main effect $(\mathrm{F}(1,21)=0.22$, $p=0.64)$. For BAS, there was no main effect of time $(\mathrm{F}(1,11)=3.74, p=0.08)$ and no study-drug main effect $(\mathrm{F}(1,21)=0.25, p=0.62)$. For SAS, there was no main effect of time $(\mathrm{F}(1,11)=3.2, p=0.1)$ and no study-drug main effect $(\mathrm{F}(1,21)=0.24, p=0.63)$.

\section{DISCUSSION}

In a group of young schizophrenia patients with minimal prior antipsychotic exposure, we found subtle global NAA reductions compared to age-matched healthy volunteers. This reduction was not related to length of untreated psychosis, symptom severity or whether subjects were or were not antipsychotic naive. However, global NAA was directly correlated to general cognitive function for the whole study sample (schizophrenia and healthy subjects), consistent with previous observations in normals (Jung et al, 1999a; 1999b; Valenzuela et al, 2000) as well across a wide range of neurological and psychiatric disorders (Ross and Sachdev, 2004). Randomized, prospective treatment with haloperidol and quetiapine, did not result in changes in NAA levels. To our knowledge, this is the first study to systematically examine the effects on NAA of two first line antipsychotics with potentially different neuromotoric side-effect profiles.

Recently, Steen et al (2005) completed the first metaanalysis of the ${ }^{1} \mathrm{H}$-MRS schizophrenia literature (64 studies: 1256 patients, 1209 healthy controls). Important findings included consistent reductions in NAA in schizophrenia, which are better documented in combined gray and white matter tissues in the medial temporal region and prefrontal lobe. Other regions with likely reductions included cingulate and parietal cortex, thalamus, and cerebellum. Also, they report no evidence of lower NAA in chronic compared to 'first episode' schizophrenia patients. Finally, the studies are almost exclusively cross-sectional (three prospective studies are discussed below). Hence, our results of NAA reductions early in the illness are consistent with this literature.

We are aware of only two other longitudinal early schizophrenia studies that assessed changes in NAA in the context of antipsychotic drug exposure (potential medication effects have also been reported in cross-sectional studies Braus et al, 2001, 2002; Bustillo et al, 2001). Choe et al (1996) found low frontal NAA/Cre at baseline with no further reductions after naturalistic treatment with typical and atypical agents (follow-up 1-6 months). Fannon et al (2003) reported reduced medial temporal NAA/Cre at baseline which was no longer statistically different from healthy subjects after 3 months of atypical antipsychotic treatment. In a study of chronically ill patients, Bertolino et al (2001) reported higher NAA/Cre in the dorsolateral prefrontal cortex in subjects treated with atypical 
antipsychotic medication compared to when they were medication free for at least 2 weeks.

Methodological differences may account for the inconsistent findings. We assessed NAA concentrations, as opposed to ratios, and corrected for CSF voxel proportion. Since schizophrenia populations have larger CSF-filled spaces (Woods, 1998), failure to do CSF-correction may overestimate schizophrenia-related metabolite reductions. We have previously documented this in a sample of chronically ill schizophrenia and control subjects (Bustillo et al, 2001): caudate NAA was significantly lower in the patients only when CSF correction was not performed. Because metabolites can vary independently (Pfefferbaum et al, 1999), use of ratios does not protect against this limitation. Finally, this is the first study of minimally treated patients prospectively followed for a longer period (mean 9 months) in a randomized, controlled design. However, our study does not settle the inconsistencies in the schizophrenia literature related to variation in ${ }^{1} \mathrm{H}$-MRS technique.

Our preliminary findings in 10 patients included in the current report, suggested frontal NAA reductions in the first year of treatment (Bustillo et al, 2002), which we have not confirmed in the completed sample. This could be due to use of different spectral fitting routine (MRUI previously and LC model currently) a change that reflects a general shift in the MRS field to use fitting algorithms with prior knowledge that consider macromolecule contributions seen at short TE (Kreis, 2004). However, a full re-analysis of the complete data set fitted with MRUI also failed to find any NAA changes overtime among haloperidol and quetiapinetreated schizophrenia and healthy control groups (data not shown). Finally, a re-analysis of the early data on the 10 initial patients fitted with LC model failed to find frontal NAA changes (paired $t$-test $=(\mathrm{df}=9)-1.85, p=0.1)$, although there was a trend for a reduction. Hence, our preliminary findings likely represent a type-I error due to a smaller sample.

The impact of typical and atypical antipsychotic drugs on NAA has been examined in four rat studies. A 1-week controlled exposure to various typical and atypical antipsychotic drugs failed to find reductions in brain NAA/ Cho (Lindquist et al, 2000). Similarly, following a 6-week exposure to haloperidol and clozapine, we detected no reductions in NAA (Bustillo et al, 2004). Recently two studies with 6 months exposures to haloperidol failed to identify NAA reductions in various cortical regions or hippocampus (Harte et al, 2005; Bustillo et al, 2006), consistent with our current findings. However, Harte et al (2005) did find striatal NAA elevations with haloperidol.

Reduced NAA may result from actual loss of neurons, reductions in their size (soma and/or processes) relative to non-neuronal tissue, or decreased intraneuronal NAA concentration due to metabolic dysfunction. The postmortem literature does not support classic neurodegenerative changes in schizophrenia with neuronal loss (Baldessarini et al, 1997). However, disease-related reductions in cortical neuropil, which include dendritic processes (Selemon et al, 1995), could result in NAA reductions, apparent early in the illness. Interestingly, a recent study in a model of early HIV brain infection in nonhuman primates, documented that NAA reductions were related to reductions in synaptophysin, a marker of synaptic integrity
(Lentz et al, 2005). Finally, there is a broad literature of hypometabolic findings in schizophrenia (Davidson and Heinrichs, 2003) and a direct relationship between NAA and PET-measured glucose metabolism in healthy and demented subjects was reported (O'Neill et al, 2000). Hence, our findings of low NAA could be due to hypometabolism and/or reduced neuropil.

The direct relationship between global NAA and general cognition (factor 1) but not with symptomatology, suggest that NAA reduction, although not disease-specific, reflects an impaired functional state apparent early in the illness. Similar cognitive-NAA relationships have been described in various neurological conditions (Ross and Sachdev, 2004) and in healthy subjects (Jung et al, 1999a). Our results with relatively short follow-up do not support further NAA reductions or normalizations with treatment. However, longitudinal long-term follow-ups of young patients will be needed to prospectively document NAA changes. Only recently, have several longitudinal MRI studies of early schizophrenia documented progressive brain volume reductions: after 2.5 years (Gur et al, 1998; Lieberman et al, 2001), 3 years (Ho, 2003) and 4 years (DeLisi et al, 1997; Rapoport et al, 1999). Hence, our mean follow-up period (9 months) may be too short to document NAA reductions.

Lower caudate Cre in the schizophrenia group was an unexpected finding and we are unaware of similar reports in the literature. Future studies are needed to corroborate this finding.

Other study limitations should be considered. First, the global baseline NAA reductions cannot be interpreted in terms of spatial specificity, since none of the four regions individually assessed were significantly different from the healthy control group. However, the significant relationship between global NAA and the general cognitive factor 1 reassures us regarding the validity of these averaged NAA measurements.

Second, the sample may be too small to detect regional differences or changes in NAA, between schizophrenia and control subjects and especially between the two treatment groups. Following the Steen et al (2005) meta-analysis and assuming a $15 \% \mathrm{CV}(2 / 13.4 * \%)$, with 32 patients and 21 controls, we could detect a $12 \%$ difference in NAA with $80 \%$ power. However, our CV's at baseline ranged from $6 \%$ (frontal controls) to $14 \%$ (caudate schizophrenia). Hence, we had $80 \%$ power to detect differences in means of 5 and $6 \%$ in frontal and occipital regions, respectively. For the more difficult to shim regions, we had $80 \%$ power to detect an $11 \%$ difference in the caudate and $10 \%$ in the cerebellum. A relevant definition of $\mathrm{CV}$ in repeated measures (baseline and last observation carried forward) is SD (of the differences in means)/mean (of the means) ${ }^{\star} 100 \%$. In the frontal region, our CV for change scores in NAA is $10 \%$. This, with samples of 23 schizophrenia and 17 control subjects, implies that we can detect $9 \%$ point difference in the longitudinal percent change of NAA between the two groups, with $80 \%$ power and $\alpha=0.05$. This is also true for the occipital and cerebellar regions ( 9 percentage point difference detectable). However, in the caudate, our CV for change scores is $16 \%$ and our detectable change difference between the two groups is $15 \%$ points.

For the patients treated with haloperidol $(N=12)$ and with quetiapine $(N=8)$ at the time of the last follow-up scan 
Table 3 Means $( \pm S D)$ for Each Metabolite in the Four Regions of Interest at Different Time Points in the Schizophrenia and Healthy Control Subjects

\begin{tabular}{|c|c|c|c|c|c|c|c|c|c|c|c|c|c|c|c|c|}
\hline \multirow[b]{2}{*}{ Region } & \multirow[b]{2}{*}{ Group } & \multicolumn{3}{|c|}{ Baseline } & \multicolumn{3}{|c|}{6 Months } & \multicolumn{3}{|c|}{12 Months } & \multicolumn{3}{|c|}{18 Months } & \multicolumn{3}{|c|}{24 Months } \\
\hline & & NAA & Cho & Cre & $N A A$ & Cho & Cre & $N A A$ & Cho & Cre & $N A A$ & Cho & Cre & $N A A$ & Cho & Cre \\
\hline \multirow[t]{2}{*}{ Caudate } & $\mathrm{Sz}$ & $\begin{array}{l}8.74 \pm 1.22 \\
n=302^{\mathrm{a}}\end{array}$ & $\begin{array}{l}1.72 \pm 0.29 \\
n=272^{\mathrm{a}} 3^{\mathrm{b}}\end{array}$ & $\begin{array}{l}6.76 \pm 1.44 \\
n=302^{\mathrm{a}}\end{array}$ & $\begin{array}{l}9.42 \pm 0.91 \\
n=182^{\mathrm{a}}\end{array}$ & $\begin{array}{l}2.07 \pm 0.63 \\
n=182^{\mathrm{a}}\end{array}$ & $\begin{array}{l}7.70 \pm 1.44 \\
n=182^{\mathrm{a}}\end{array}$ & $\begin{array}{l}8.79 \pm 0.71 \\
n=132^{\mathrm{a}}\end{array}$ & $\begin{array}{l}1.81 \pm 0.29 \\
n=132^{\mathrm{a}}\end{array}$ & $\begin{array}{l}7.03 \pm 1.07 \\
n=132^{\mathrm{a}}\end{array}$ & $\begin{array}{l}9.71 \pm 0.86 \\
n=6\end{array}$ & $\begin{array}{l}2.03 \pm 0.32 \\
n=6\end{array}$ & $\begin{array}{l}7.79 \pm 0.33 \\
n=6\end{array}$ & $\begin{array}{l}8.93 \pm 0.99 \\
n=5\end{array}$ & $\begin{array}{l}2.36 \pm 0.29 \\
n=5\end{array}$ & $\begin{array}{l}8.29 \pm 1.18 \\
n=5\end{array}$ \\
\hline & Con & $\begin{array}{l}9.29 \pm 1.00 \\
n=192^{\mathrm{a}}\end{array}$ & $\begin{array}{l}1.90 \pm 0.29 \\
n=192^{\mathrm{a}}\end{array}$ & $\begin{array}{l}7.61 \pm 0.93 \\
n=192^{\mathrm{a}}\end{array}$ & $\begin{array}{l}8.93 \pm 0.74 \\
n=161^{\mathrm{a}}\end{array}$ & $\begin{array}{l}1.99 \pm 0.35 \\
n=\left.16\right|^{\mathrm{a}}\end{array}$ & $\begin{array}{l}7.70 \pm 1.17 \\
n=161^{\mathrm{a}}\end{array}$ & $\begin{array}{l}9.40 \pm 1.50 \\
n=9\end{array}$ & $\begin{array}{l}2.03 \pm 0.29 \\
n=9\end{array}$ & $\begin{array}{l}7.89 \pm 1.32 \\
n=9\end{array}$ & & & & & & \\
\hline \multirow[t]{2}{*}{ Frontal } & $\mathrm{Sz}$ & $\begin{array}{l}9.06 \pm 0.78 \\
n=32\end{array}$ & $\begin{array}{l}1.72 \pm 0.37 \\
n=32\end{array}$ & $\begin{array}{l}5.68 \pm 0.83 \\
n=32\end{array}$ & $\begin{array}{l}9.26 \pm 0.97 \\
n=21\end{array}$ & $\begin{array}{l}1.78 \pm 0.41 \\
n=21\end{array}$ & $\begin{array}{l}5.63 \pm 1.02 \\
n=21\end{array}$ & $\begin{array}{l}9.07 \pm 0.72 \\
n=15\end{array}$ & $\begin{array}{l}1.67 \pm 0.31 \\
n=15\end{array}$ & $\begin{array}{l}5.43 \pm 0.62 \\
n=15\end{array}$ & $\begin{array}{l}9.40 \pm 0.57 \\
n=6\end{array}$ & $\begin{array}{l}1.77 \pm 0.34 \\
n=6\end{array}$ & $\begin{array}{l}5.46 \pm 0.98 \\
n=6\end{array}$ & $\begin{array}{l}8.91 \pm 0.54 \\
n=5\end{array}$ & $\begin{array}{l}1.98 \pm 0.31 \\
n=5\end{array}$ & $\begin{array}{l}5.55 \pm 0.60 \\
n=5\end{array}$ \\
\hline & Con & $\begin{array}{l}9.40 \pm 0.64 \\
n=21\end{array}$ & $\begin{array}{l}1.79 \pm 0.27 \\
n=21\end{array}$ & $\begin{array}{l}5.56 \pm 0.43 \\
n=21\end{array}$ & $\begin{array}{l}9.36 \pm 0.44 \\
n=17\end{array}$ & $\begin{array}{l}1.75 \pm 0.20 \\
n=17\end{array}$ & $\begin{array}{l}5.59 \pm 0.47 \\
n=17\end{array}$ & $\begin{array}{l}9.21 \pm 0.44 \\
n=9\end{array}$ & $\begin{array}{l}1.72 \pm 0.12 \\
n=9\end{array}$ & $\begin{array}{l}5.56 \pm 0.55 \\
n=9\end{array}$ & & & & & & \\
\hline \multirow[t]{2}{*}{ Occipital } & $\mathrm{Sz}$ & $\begin{array}{l}9.94 \pm 0.79 \\
n=32\end{array}$ & $\begin{array}{l}1.66 \pm 0.26 \\
n=32\end{array}$ & $\begin{array}{l}5.75 \pm 0.79 \\
n=32\end{array}$ & $\begin{array}{l}9.95 \pm 1.11 \\
n=21\end{array}$ & $\begin{array}{l}1.71 \pm 0.36 \\
n=21\end{array}$ & $\begin{array}{l}5.54 \pm 1.00 \\
n=21\end{array}$ & $\begin{array}{l}9.94 \pm 0.72 \\
n=15\end{array}$ & $\begin{array}{l}1.64 \pm 0.29 \\
n=15\end{array}$ & $\begin{array}{l}5.36 \pm 0.35 \\
n=15\end{array}$ & $\begin{array}{l}9.86 \pm 0.89 \\
n=6\end{array}$ & $\begin{array}{l}1.73 \pm 0.35 \\
n=6\end{array}$ & $\begin{array}{l}5.70 \pm 0.72 \\
n=6\end{array}$ & $\begin{array}{l}9.76 \pm 0.85 \\
n=5\end{array}$ & $\begin{array}{l}1.80 \pm 0.39 \\
n=5\end{array}$ & $\begin{array}{l}5.57 \pm 0.60 \\
n=5\end{array}$ \\
\hline & Con & $\begin{array}{l}10.14 \pm 0.80 \\
n=21\end{array}$ & $\begin{array}{l}1.71 \pm 0.20 \\
n=21\end{array}$ & $\begin{array}{l}5.36 \pm 0.36 \\
n=21\end{array}$ & $\begin{array}{l}9.99 \pm 0.53 \\
n=17\end{array}$ & $\begin{array}{l}1.66 \pm 0.20 \\
n=17\end{array}$ & $\begin{array}{l}5.23 \pm 0.46 \\
n=17\end{array}$ & $\begin{array}{l}9.61 \pm 0.70 \\
n=9\end{array}$ & $\begin{array}{l}1.62 \pm 0.20 \\
n=9\end{array}$ & $\begin{array}{l}4.99 \pm 0.61 \\
n=9\end{array}$ & & & & & & \\
\hline \multirow[t]{2}{*}{ Cerebellar } & $\mathrm{Sz}$ & $\begin{array}{l}9.59 \pm 0.87 \\
n=32\end{array}$ & $\begin{array}{l}1.86 \pm 0.22 \\
n=32\end{array}$ & $\begin{array}{l}8.07 \pm 0.84 \\
n=32\end{array}$ & $\begin{array}{l}9.66 \pm \mid .41 \\
n=20 I^{\mathrm{a}}\end{array}$ & $\begin{array}{l}1.85 \pm 0.33 \\
n=\left.20\right|^{\mathrm{a}}\end{array}$ & $\begin{array}{l}7.91 \pm 1.31 \\
n=\left.20\right|^{\mathrm{a}}\end{array}$ & $\begin{array}{l}9.85 \pm 0.85 \\
n=|4|^{\mathrm{a}}\end{array}$ & $\begin{array}{l}1.91 \pm 0.18 \\
n=141^{\mathrm{a}}\end{array}$ & $\begin{array}{l}7.81 \pm 0.85 \\
n=\left.14\right|^{\mathrm{a}}\end{array}$ & $\begin{array}{l}9.99 \pm 0.98 \\
n=42^{a}\end{array}$ & $\begin{array}{l}1.95 \pm 0.26 \\
n=42^{a}\end{array}$ & $\begin{array}{l}8.13 \pm 0.49 \\
n=42^{a}\end{array}$ & $\begin{array}{l}9.03 \pm 2.19 \\
n=5\end{array}$ & $\begin{array}{l}1.87 \pm 0.46 \\
n=5\end{array}$ & $\begin{array}{l}7.67 \pm 1.72 \\
n=5\end{array}$ \\
\hline & Con & $\begin{array}{l}9.81 \pm 1.21 \\
n=192^{\mathrm{a}}\end{array}$ & $\begin{array}{l}1.98 \pm 0.32 \\
n=192^{\mathrm{a}}\end{array}$ & $\begin{array}{l}7.90 \pm 0.79 \\
n=192^{\mathrm{a}}\end{array}$ & $\begin{array}{l}9.78 \pm 1.39 \\
n=17\end{array}$ & $\begin{array}{l}2.05 \pm 0.22 \\
n=17\end{array}$ & $\begin{array}{l}8.05 \pm 0.64 \\
n=17\end{array}$ & $\begin{array}{l}9.55 \pm 1.12 \\
n=9\end{array}$ & $\begin{array}{l}1.92 \pm 0.24 \\
n=9\end{array}$ & $\begin{array}{l}7.73 \pm 0.78 \\
n=9\end{array}$ & & & & & & \\
\hline
\end{tabular}

Abbreviations: NAA, N-acetyl-aspartate; Cho, choline; Cre, creatine; Sz, schizophrenia group; Con, healthy control group; $n$, number of spectra analyzed; FWHM, full-width half-maximum; SD, standard deviation. ${ }^{a}$ Number of spectra rejected because of FWHM $>0.1$ p.p.m.

${ }^{b}$ Number of spectra rejected because of $\% \mathrm{SD}>20$. 
the CVs for change scores in NAA varied from $10 \%$ (cerebellar) to $16 \%$ (caudate). Hence with the smaller sample sizes, we had $80 \%$ power to detect a percentage point difference greater than 13 (in the cerebellum) and than 22 (in the caudate), between the two-drug treatment. Although the animal studies have consistently failed to document lowering of NAA with typical or atypical antipsychotics drugs, it remains possible that, as suggested by Bertolino et al (2001), atypical antipsychotic agents may increase NAA in schizophrenia, though probably not to normal levels. Furthermore, the grouping of multiple doses of quetiapine and haloperidol may have reduced potential medication effects.

Third, our analyses of slopes may be confounded by different length of follow-ups among the subjects. If there is a linear effect of time (due to disease progression or medication exposure) our approach is not biased but length of follow-up may be insufficient for some subjects. However, if the effect of time is nonlinear, and eg NAA reduction occurs early (eg 3-6 months), combining subjects with short and longer follow-ups may obscure the effects on slopes (ie subjects followed longer may present smaller slopes because the NAA loss took place earlier). Hence, we classified the duration of follow-up over which slopes were computed as long and short based on a median cut score (10 months). Adjusting our analyses for this variable did not change the finding that NAA slopes did not differ between groups. However, there was a trend $(\mathrm{F}(1,31)=3.71$, $p=0.06$ ) suggestive that longer durations of follow-up were associated with steeper (more negative) slopes.

Fourth, the spectroscopic voxels were large involving various functionally dissimilar areas and included different proportions of CSF, gray and white matter, making interpretations regarding tissue specificity problematic. We minimized this latter limitation by correcting for CSF proportion. Also, covariation for gray/white matter proportions in each voxel did not change the results.

Fifth, our technique at $1.5 \mathrm{~T}$ did not have enough spectral resolution to reliably separate NAA from NAAG (SD\% were significantly better for NAA + NAAG than for NAA, data not shown), so like in all our previous human work, we report combined NAA plus NAAG. As discussed in Edden et al (2007), independent quantification of NAA and NAAG at $1.5 \mathrm{~T}$ is challenging since the more intense upfield peaks ( $\sim 2$ p.p.m.) are only separated by 0.03 p.p.m. and the less overlapping resonances are compromised by water suppression. Accordingly, the NAA + NAAG output that simultaneously covaries the fits for NAA and NAAG is a more reliable measurement.

Sixth, schizophrenia patients had been psychotic for many months before the initial scan, so it is possible that we missed the most active period of NAA reductions concurrent with onset of psychosis. Finally, patients were moderately psychotic at intake and it is possible that severely psychotic subjects would demonstrate significant metabolic changes overtime.

In summary, these results suggest that subtle NAA reductions are present early in schizophrenia and underlie the general cognitive impairments, independent of symptomatic state or treatment. The mechanisms that account for NAA reductions remain unknown. One influential model of psychosis proposes an excitotoxic glutamatergic mechanism
(Olney and Farber (1995)) that may lead to NAA and volume reductions and impaired functional outcome in schizophrenia. The application of short-echo spectroscopic techniques at higher field strength may permit to test glutamatergic dysfunction in vivo.

\section{ACKNOWLEDGEMENTS}

The study was supported by the Mental Illness and Neuroscience Discovery Institute (DE-FG03-99ER62764/ A002) and Investigator-initiated Study Astra-Zeneca Research award (IRUSQUET no. 0021) to J Bustillo, MD. Dr Brooks is supported in part by NIH grant NS039123. The authors are grateful to Ranee Barrow, William Horan, Elma Landgraf, Allan Schmitt, Catie Snider, Lisa Thomson, Mia Touchet, Mariebeth Velasquez, and Christina Wolff for their contribution to this study.

\section{DISCLOSURE/CONFLICT OF INTEREST}

Juan Bustillo received an Investigator-initiated Study award from Astra-Zeneca (makers of quetiapine) to partially support this study. He has no other potential conflicts of interest to disclose.

John Lauriello received grant support and has been a consultant for Eli Lilly, Pfizer, and Janssen. He has also been in the Speakers Bureau for Janssen, Bristol Myers Squibb, Pfizer, and Astra-Zeneca.

Laura Rowland, Rex Jung, William Brooks, Clifford Qualls, Roger Hammond, and Blaine Hart have no conflict of interest to report.

\section{REFERENCES}

Baldessarini RJ, Hegarty JD, Bird ED, Benes FM (1997). Meta-analysis of postmortem studies of Alzheimer's disease-like neuropathology in schizophrenia. Am J Psychiatry 154: 861-863.

Barker PB, Soher BJ, Blackband SJ, Chatham JC, Mathews VP, Bryan RN (1993). Quantitation of proton NMR spectra of the human brain using tissue water as an internal concentration standard. NMR Biomed 6: 89-94.

Barnes TR (1989). A rating scale for drug-induced akathisia. $\mathrm{Br} J$ Psychiatry 154: 672-676.

Bertolino A, Callicott JH, Mattay VS, Weidenhammer KM, Rakow R, Egan MF et al (2001). The effect of treatment with antipsychotic drugs on brain $\mathrm{N}$-acetylaspartate measures in patients with schizophrenia. Biol Psychiatry 49: 39-46.

Braus DF, Ende G, Weber-Fahr W, Demirakca T, Henn FA (2001). Favorable effect on neuronal viability in the anterior cingulate gyrus due to long-term treatment with atypical antipsychotics: an MRSI study. Pharmacopsychiatry 34: 251-253.

Braus DF, Ende G, Weber-Fahr W, Demirakca T, Tost H, Henn FA (2002). Functioning and neuronal viability of the anterior cingulate neurons following antipsychotic treatment: MR-spectroscopic imaging in chronic schizophrenia. Eur Neuropsychopharmacol 12: 145-152.

Brooks WM, Friedman SD, Stidley CA (1999a). Reproducibility of ${ }^{1} \mathrm{H}-\mathrm{MRS}$ in vivo. Magn Reson Med 40: 193-197.

Brooks WM, Jung RE, Ford CC, Greinel EJ, Sibbitt Jr WL (1999b). Relationship between neurometabolite derangement and neurocognitive dysfunction in systemic lupus erythematosus. J Rheumatol 26: 81-85.

Brooks WM, Wesley MH, Kodituwakku P, Garry P, Rosenberg GA (1997). H-MRS differentiates white matter hyperintensities in 
subcortical arteriosclerotic encephalopathy from those in normal elderly. Stroke 28: 1940-1943.

Bustillo J, Barrow R, Paz R, Tang J, Seraji-Bozorgzad N, Moore G et al (2006). Long term treatment of rats with haloperidol: lack of an effect on brain $\mathrm{N}$-acetyl aspartate levels. Neuropsychopharmacology 31: 751-756.

Bustillo J, Lauriello J, Rowland L, Thomson L, Petropoulos H, Hammond $\mathrm{R}$ et al (2002). Longitudinal follow-up of neurochemical changes during the first year of antipsychotic treatment in schizophrenia patients with minimal previous medication exposure. Schizophr Res 58: 313-321.

Bustillo J, Wolff C, Myers-y-Gutierrez A, Dettmer T, Cooper T, Allan A et al (2004). Treatment of rats with antipsychotic drugs: lack of an effect on N acetyl-aspartate levels. Schizophr Res 66: 31-39.

Bustillo JR, Lauriello J, Rowland LM, Jung RE, Petropoulos H, Hart BL et al (2001). Effects of chronic haloperidol and clozapine treatments on frontal and caudate neurochemistry in schizophrenia. Psychiatry Res 107: 135-149.

Choe BY, Suh TS, Shinn KS, Lee CW, Lee C, Paik IH (1996). Observation of metabolic changes in chronic schizophrenia after neuroleptic treatment by in vivo hydrogen magnetic resonance spectroscopy. Invest Radiol 6: 345-352.

Davidson LL, Heinrichs RW (2003). Quantification of frontal and temporal lobe brain-imaging findings in schizophrenia: a metaanalysis. Psychiatry Res 122: 69-87.

DeLisi LE, Sakuma M, Tew W, Kushner M, Hoff AL, Grimson R (1997). Schizophrenia as a chronic brain process: a study of progressive brain structural change subsequent to the onset of schizophrenia. Psychiatry Res 74: 129-140.

Edden RA, Pomper M, Barker P (2007). In vivo differentiation of N-Acetyl Aspartyl Glutamate and N-Acetyl Aspartate at 3 Tesla. Magn Reson Med 57: 977-982.

Fannon D, Simmons A, Tennakoon L, O'Ceallaiagh S, Sumich A, Doku V et al (2003). Selective deficit of hippocampal $\mathrm{N}$-acetylaspartate in antipsychotic-naïve patients with schizophrenia. Biol Psychiatry 54: 587-598.

First MB, Spitzer RL, Gibbon M, Williams JBW (1995a). Structured Clinical Interview for DSM-IV Axis I Disorders, Patient Edition (SCID-P), version $2 \mathrm{New}$ York State Psychiatric Institute, Biometrics Research: New York.

First MB, Spitzer RL, Gibbon M, Williams JBW (1995b). Structured Clinical Interview for DSM-IV Axis I Disorders, Non-Patient Edition (SCID-NP), version 2 New York State Psychiatric Institute, Biometrics Research: New York.

Friedman SD, Stidley CA, Brooks WM, Hart BL, Sibbitt Jr WL (1998). Brain injury and neurometabolic abnormalities in systemic lupus erythematosus. Radiology 209: 79-84.

Gur RE, Cowell P, Turetsky BI, Gallagher F, Cannon T, Bilker W et al (1998). A follow-up magnetic resonance imaging study of schizophrenia. Arch Gen Psychiatry 55: 145-152.

Guy W (1976). ECDEU Assessment Manual for Psychopharmacology: Publication ADM 76-338. US Department of Health, Education and Welfare: Washington, DC, pp 534-537.

Harte MK, Bachus SB, Reynolds GP (2005). Increased $\mathrm{N}$-acetylaspartate in rat striatum following long-term administration of haloperidol. Schizophr Res 75: 303-308.

Ho BC, Andreasen NC, Nopoulos P, Arndt S, Magnotta V, Flaum M (2003). Progressive structural brain abnormalities and their relationship to clinical outcome: a longitudinal magnetic resonance imaging study early in schizophrenia. Arch Gen Psychiatry 60: 585-594.

Jensen AR (1998). The G Factor: The Science of Mental Ability. Praeger: Westport.

Jung RE, Yeo RA, Chiulli SJ, Sibbitt Jr WL, Weers DC, Hart BL et al (1999a). Biochemical markers of cognition: a proton MR spectroscopy study of normal human brain. Neuroreport 10: $3327-3331$.
Jung RE, Brooks WM, Yeo RA, Chiulli SJ, Weers DC, Sibbitt Jr WL (1999b). Biochemical markers of intelligence: a proton MR spectroscopy study of normal human brain. Proc Biol Sci 266: 1375-1379.

Jung RE, Yeo RA, Love TM, Petropoulos H, Sibbitt WL, Brooks WM (2002). Biochemical markers of mood: a proton MR spectroscopy study of normal human brain. Biol Psychiatry 51: 224-229.

Kay SR, Fiszbein A, Opler LA (1987). The Positive and Negative Syndrome Scale (PANSS) for schizophrenia. Schizophr Bull 13: 261-276.

Kreis R (2004). Issues of spectral quality in clinical ${ }^{1} \mathrm{H}$-magnetic resonance spectroscopy and a gallery of artifacts. NMR Biomed 17: $361-381$

Lentz M, Kim J, Westmoreland S, Greco J, Fuller R, Ratai E et al (2005). Quantitative neuropathologic correlates of changes in ratio of $\mathrm{N}$-acetylaspartate to creatine in macaque brain. Radiology 235: 461-468.

Lezak MD, Howleson DB, Loring DW, Hannay HJ, Fischer JS (2004). Neuropsychological Assessment. 4th edn. Oxford University Press: New York, 1,016 pp.

Lieberman J, Chakos M, Wu H, Alvir J, Hoffman E, Robinson D et al (2001). Longitudinal study of brain morphology in first episode schizophrenia. Biol Psychiatry 49: 487-499.

Lindquist DM, Hawk RM, Karson CN, Komoroski RA (2000). Effects of antipsychotic drugs on metabolite ratios in rat brain in vivo. Magn Reson Med 43: 355-358.

Mullins P, Rowland L, Bustillo J, Bedrick E, Lauriello J, Brooks W (2003). Reproducibility of H-MRS measurements in schizophrenic patients. Magn Reson Med 50: 704-707.

O'Neill J, Eberling JL, Schuff N, Jagust W, Reed B, Soto G et al (2000). Method to correlate ${ }^{1} \mathrm{H}$ MRSI and ${ }^{18}$ FDG-PET. Magn Reson Med 43: 244-250.

Olney JW, Farber NB (1995). Glutamate receptor dysfunction and schizophrenia. Arch Gen Psychiatry 52: 998-1007.

Petropoulos H, Brooks WM, Sibbitt Jr WL (1999). Automated T2 quantitation in neuropsychiatric lupus erythematosus: a marker of active disease. J Magn Reson Imaging 9: 39-43.

Pfefferbaum A, Adalsteinsson E, Spielman D, Sullivan EV, Lim KO (1999). In vivo spectroscopic quantification of the $N$-acetyl moiety, creatine, and choline from large volumes of brain gray and white matter: effects of normal aging. Magn Reson Med 41: 276-284.

Provencher S (1993). Estimation of metabolite concentrations from localized in vivo proton NMR spectra. Magn Reson Med 30: 672-679.

Rapoport JL, Giedd JN, Blumenthal J, Hamburger S, Jeffries N, Fernandez $\mathrm{T}$ et al (1999). Progressive cortical change during adolescence in childhood-onset schizophrenia. A longitudinal magnetic resonance imaging study. Arch Gen Psychiatry 56: 649-654.

Ross AJ, Sachdev PS (2004). Magnetic resonance spectroscopy in cognitive research. Brain Res Brain Res Rev 44: 83-102.

Selemon LD, Rajkowska G, Goldman-Rakic PS (1995). Abnormally high neuronal density in the schizophrenic cortex. Arch Gen Psychiatry 52: 805-819.

Simpson GM, Angus JW (1970). A rating scale for extrapyramidal side-effects. Acta Psychiatr Scand Suppl 212: 11-19.

Spearman C (1904). General intelligence, objectively determined and measured. Am J Psychol 15: 201-293.

Steen RG, Hamer RM, Lieberman JA (2005). Measurement of brain metabolites by ${ }^{1} \mathrm{H}$ magnetic resonance spectroscopy in patients with schizophrenia: a systematic review and meta-analysis. Neuropsychopharmacology 30: 1949-1962.

Valenzuela MJ, Sachdev PS, Wen W, Shnier R, Brodaty H, Gillies D (2000). Dual voxel proton magnetic resonance spectroscopy in the healthy elderly: subcortical-frontal axonal $\mathrm{N}$-acetylaspartate levels are correlated with fluid cognitive abilities independent of structural brain changes. Neuroimage 12: 747-756. 
Wechsler D (1997). Wechsler Adult Intelligence Scale: Administration and Scoring Manual 3rd edn. The Psychological Corporation and Harcourt Brace: San Antonio.

Weiner MW, Hetherington H, Hubesch B, Karczmar G, Massie B, Maudsley A et al (1989). Clinical magnetic resonance spectroscopy

of brain, heart, liver, kidney, and cancer. A quantitative approach. NMR Biomed 2: 290-297.

Woods BT (1998). Is schizophrenia a progressive neurodevelopmental disorder? Towards a unitary pathogenetic mechanism. Am J Psychiatry 155: 1661-1670. 